\title{
Articulaciones del conocimiento ecológico desarrollado en las prácticas de localidad con el conocimiento científico: una etnografía de una pesquería artesanal en Uruguay
}

\author{
ARTICULATIONS OF ECOLOGICAL KNOWLEDGE DEVELOPED IN LOCAL \\ PRACTICES WITH SCIENTIFIC KNOWLEDGE: AN ETHNOGRAPHY OF AN \\ ARTISANAL FISHERY IN URUGUAY \\ ARTICULAÇÕES DO CONHECIMENTO ECOLÓGICO DESENVOLVIDO NAS PRÁTICAS \\ LOCAIS COM O CONHECIMENTO CIENTÍFICO: UMA ETNOGRAFIA DE UMA \\ PESCARIA ARTESANAL NO URUGUAI \\ Leticia D'Ambrosio* \\ Gastón Martínez** \\ Inti Clavijo*** \\ Viviana Cuberos***1 \\ treboles@gmail.com \\ Recibido: 5/2/2020 Aceptado: 28/8/2020
}

\begin{abstract}
Resumen
Desde hace más de 60 años en la zona comprendida entre Barra del Chuy y La Coronilla, en 22 kilómetros de faja costera en el Este del Uruguay, se extrae la almeja amarilla Amarillodesma mactroides. Durante todas estas décadas, la explotación de dicho recurso ha atravesado grandes variaciones. En este proceso, para la implementación de la regulación estatal se han vinculado a la pesquería diferentes actores sociales provenientes del Estado y la Universidad. Por medio de la investigación etnográfica, se han ido relevando las relaciones y vinculaciones de los actores sociales y tipos de conocimientos en diálogo y algunas veces en pugna. Este trabajo busca contribuir a la comprensión de la complejidad político-social y económica en procesos de comanejo de pesquerías artesanales y poniendo énfasis en las articulaciones entre conocimientos diversos. Asimismo destacamos la oportunidad que brinda la investigación etnográfica para conocer las perspectivas de distintos actores involucrados en procesos de co-manejo, entre otros aspectos. Este artículo expone los diferentes elementos que emergen en el diálogo de saberes, al momento de decidir sobre la regulación y protección de los recursos pesqueros, así como las implicancias para quienes trabajan en la extracción y/o comercialización de los mismos.
\end{abstract}

Palabras clave: Conocimiento ecológico, Prácticas de la localidad, Co-manejo, Pesquerías artesanales, Uruguay

\footnotetext{
$1 *$ Centro Universitario Regional Este/Universidad de la República

** Grupo de Estudios Pesqueros y de Impacto Ambiental

*** Centro de Investigaciones del Patrimonio Costero del Centro Universitario de la Región Este
}

Tekoporá ${ }^{\circledR}$. Centro Universitario de la Región Este. Universidad de la República (C) D'Ambrosio et al. (2020)

Este es un artículo de Acceso Abierto distribuido bajo licencia Creative Commons (CC BY NC 4.0) 


\begin{abstract}
For over 60 years the yellow clam Amarillodesma mactroides has been extracted in the area between Barra del Chuy and La Coronilla, in 22 kilometers of the coastal strip in eastern Uruguay. During all these decades, the exploitation of this resource has gone through great variations. In this process, different social actors from the State and the University have been connected to the fishery to implement state regulation. Through ethnographic research, it has been gathered data regarding the relationships and linkages of the diverse social actors and the types of knowledge, sometimes in dialogue and others in conflict. With this work, we seek to contribute to the understanding of the political-social and economic complexity of the comanagement processes in artisanal fisheries and in particular to emphasize the articulations between diverse knowledge. Furthermore, we highlight the opportunity that ethnographic research offers us to know the perspectives of the different actors involved in the co-management processes, among other aspects. This article exposes the different factors involved in the dialogue of knowledge, when deciding on the regulation and protection of fishery resources and the implications for those who manage their extraction and or commercialization.
\end{abstract}

Keywords: Ecological knowledge, Local practices, Co-management, Artisanal fisheries, Uruguay

\title{
Resumo
}

Desde mais de 60 anos na zona compreendida entre Barra del Chuy e o balneário La Coronilla nos 22 quilômetros de faixa costeira no Este do Uruguai, é praticada a extração da "almeja amarilla" Amarillodesma mactroides. Durante estas décadas, a exploração do recurso tem atravessado grandes variações. Em este processo, para a implementação da regulação estatal tem sido vinculado à pescaria diferentes atores sociais provenientes do Estado e a Universidade. Por meio da pesquisa etnográfica, tem sido relevadas as relações e vinculações dos diferentes atores sociais e os tipos de conhecimentos em diálogo, e às vezes em pugna. Este trabalho busca contribuir à compreensão da complexidade político-social e econômica nos processos de cogestão de pescarias artesanais focando o ênfase nas articulações entre conhecimentos diversos. Da mesma forma destacamos a oportunidade que fornece a pesquisa etnográfica para conheces as perspectivas de diferentes atores envolvidos em processos de cogestão, entre outros aspetos. Este artigo expõe os diferentes elementos que emergem no diálogo de saberes, ao momento das toma de decisões sobre a regulação e proteção de recursos pesqueiros, assim como as implicações para aqueles que trabalha da extração e/ou comercialização de eles.

Palavras chave: Conhecimento ecológico, Práticas locais, Cogestão, Pesca artesanal, Uruguai

\section{Introducción}

Este artículo busca analizar los flujos, intercambios y conexiones entre conocimientos en un caso de estudio de una pesquería artesanal en la Costa Este de Uruguay. A partir de la investigación etnográfica llevada adelante durante el 2018 , se revelaron diferentes lazos entre los pescadores de costa que participan de la actividad, y varios agentes relacionados a las ciencias biológicas y la gestión del recurso desde el Estado Uruguayo. A partir del discurso de los actores sobre el proceso histórico de gestión del recurso "almeja amarilla" se evidencian vínculos de poder, jerarquías e influencias, por momentos opacos para la discursividad oficial desde la cual se gestionan y toman las decisiones sobre la pesquería.

Por medio del análisis del material etnográfico y a partir de los marcos conceptuales producidos en casos etnográficos similares, se presenta una caracterización general de la pesquería sobre las siguientes dimensiones: conocimientos ecológicos desarrollados en las prácticas de la localidad (su articulación con otros conocimientos), fases y modalidades de manejo de la pesquería, agencia de humanos y no humanos en relación a la especie Amarilladesma mactroides (Reeve, 1854c) y su mortandad masiva. Además se analizan las particularidades del caso etnografiado para construir conocimiento sobre los diálogos de saberes y de cómo ello puede ser un insumo para mejorar los procesos de gestión de los recursos, apostando a una mejora en la interacción durante los procesos participativos. Consideramos que relevar el conocimiento desarrollado en las prácticas de la localidad y sus 
articulaciones, puntos de contacto, con el conocimiento científico aplicado a la gestión del recurso objeto de la pesquería estudiada, puede propiciar su complementariedad y generar un co-manejo que lo contemple integralmente.

\section{Materiales y Métodos}

En esta investigación se llevó a cabo trabajo de campo etnográfico, principalmente observación participante y entrevistas en profundidad. Con esta aproximación etnográfica buscamos captar la perspectiva de los "almejeros" sobre diversas temáticas transversales a la pesquería. En total se realizaron diez entrevistas semiestructuradas, las cuales fueron desgrabadas y sistematizadas por categorías de análisis, asimismo se realizaron entrevistas etnográficas, buscando con estas el rol activo de los interlocutores en la elección de los temas a tratar.

Además del trabajo directo con los interlocutores se hizo un relevamiento y sistematización bibliográfica de antecedentes históricos y documentales en diferentes reservorios públicos y personales.

\section{Área de Estudio}

La zona donde se realiza la extracción de la almeja amarilla comprende un cinturón arenoso de playa de 22 kilómetros de línea de costa entre el balneario La Coronilla y el conocido como La Barra del Chuy (Rocha), limítrofe con el balneario de igual nombre en Brasil (Figura 01). Se observa la llegada a la zona de muchas de las familias actuales de almejeros hacia la década de 1960. Dicha llegada estuvo vinculada a la construcción de las diferentes etapas del Canal Andreoni , la Salinera, el desarrollo de sociedades pecuarias y del cultivo del arroz, y el

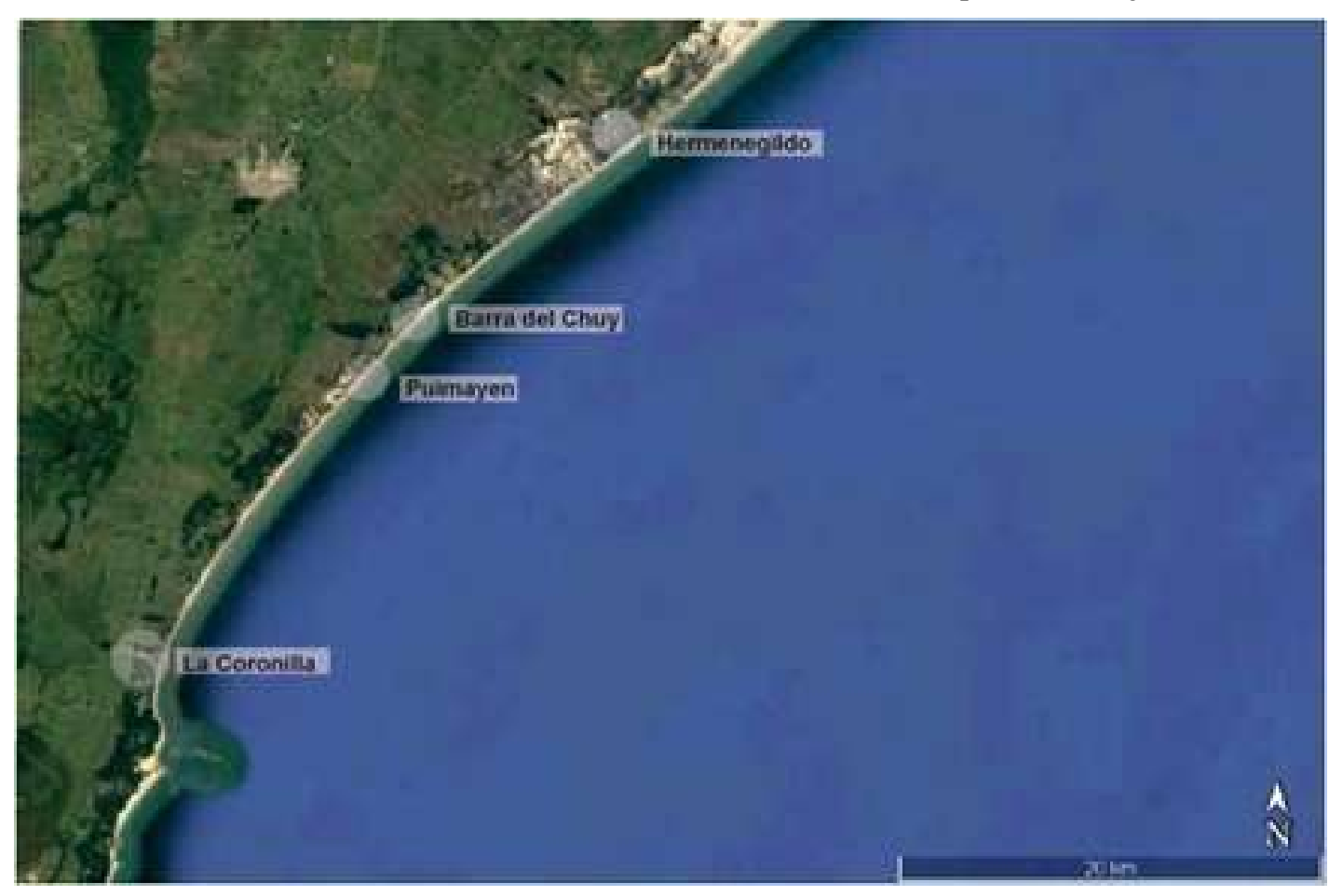

desarrollo del balneario más atlántico de Uruguay así como también de las fábricas de conservas en Palmares de La Coronilla y las ubicadas sobre el $\mathrm{A}^{\circ}$ Chuy. Este proceso fue conformando también a las localidades de La

Barra del Chuy. Figura 01: Mapa satelital 22 km. de costa de Coronilla a Barra del Chuy. 
Toda esta zona tiene elementos y actividades comunes durante el año. Algunos de estos refieren a la cercanía de la frontera con Brasil, la vinculación de la costa con el área rural, la marcada estacionalidad en alguna de las principales actividades productivas, las cuales están fuertemente vinculadas al turismo y a la temporada veraniega. En la época del verano la gastronomía, la hotelería y los servicios asociados al turismo de sol y playa producen un incremento significativo en los movimientos económicos de la zona por la migración de nacionales y extranjeros. Actualmente la zafra de la almeja amarilla coincide con la temporada turística, habilitándose la extracción de esta especie durante toda la estación del verano (diciembre-semana de turismo) y más allá de ella, si ocurren fenómenos de mareas rojas durante la temporada de verano que llevan a establecer veda de extracción temporal.

\section{Proceso de extracción y comercialización}

Los procesos de extracción y venta se han visto beneficiados por la actividad gastronómica en la costa este de Uruguay puesto que una importante parte de la venta de almejas ha estado destinada a los restoranes que se encuentran trabajando en su pico más alto durante esta época. Antiguamente la almeja consistía en un producto destinado casi exclusivamente a la carnada para pesca deportiva (e.g. pesca de corvina negra en primavera). Entre 2009 y 2011, la almeja se vendía como carnada para pesca deportiva tanto a nivel local como al Departamento de Maldonado, a intermediarios ya reconocidos en la pesquería, y/o directamente a los quioscos de venta de mariscos en el Puerto de Punta del Este. Estos últimos "purgaban" la almeja en el puerto y la vendían a los restoranes de la zona. A partir del año 2012 tras ciertos cambios vinculados al procesamiento y a la comercialización, así como a transformaciones institucionales, los cuales mencionaremos más adelante, la especie se ha convertido en un producto de gran valor en el circuito gastronómico en distintos sitios del Este del país; ha cobrado un valor culinario sumamente relevante en el escenario nacional y global, al punto que es uno de los ocho recursos que forman parte del Arca del Gusto de Slowfood en Uruguay.

En la extracción se involucran, por lo general, todos los miembros de las familias, desde los más jóvenes hasta los más viejos. Existen casos de familias paradigmáticas en este sentido pues hay hasta tres generaciones "trabajando la almeja" y que incluso cuando están más viejos o tienen algún problema de salud se asocian con otros miembros de la familia para que los ayuden con las tareas más demandantes en lo que respecta al esfuerzo físico. Es común que entre los miembros de la familia se distribuyan las distintas etapas que involucran "el trabajar" con la almeja. Una almejera relataba que ya desde los dos años de edad aproximadamente los niños aprenden, por ejemplo, a reconocer dónde está el cardumen , donde pueden pisar y dónde no y demás conocimientos asociados con "arrancar la almeja". Junto con la transmisión de la modalidad de extracción de las almejas, se valora y se transmite, en prácticas cotidianas de la pesquería, el cuidado de las almejas más pequeñas a los más chicos de las familias, podríamos decir que hay una mirada positiva hacia el cuidado de la especie.

Es habitual que los almejeros alternen la pesquería de la almeja con otras zafras, en momentos de vedas cuando no pueden arrancar almejas, entonces se dedican a trabajar la leña, o a otros trabajos zafrales.

A lo largo de los últimos sesenta años, desde que se comenzó la extracción hasta el presente, el recurso ha atravesado diferentes momentos. Los diferentes períodos pueden caracterizarse de acuerdo con diversos aspectos que tienen que ver con la forma de extracción, 
de venta, de intermediación de la almeja, sus formas de procesamiento y la valorización del recurso. En la siguiente sección proponemos una periodización de este proceso, tomando en cuenta algunos elementos relevantes para el objetivo de este artículo.

\section{Resultados y discusión}

\section{1- Períodos en la extracción de la pesquería de la almeja}

Los inicios de la extracción de almeja (libre acceso) (1960-1986)

Los relatos de los primeros tiempos de la extracción de almeja hablan de una práctica desarrollada a través de redes familiares y de amistad. Los mismos almejeros de la actualidad siendo niños de menos de 10 años frecuentaban la playa junto a sus familias para extraer almejas con la mano. A partir de ese momento la extracción fue aumentando y la actividad se fue popularizando.

En este período se dieron las mayores extracciones del recurso. De acuerdo con los relatos de interlocutores, el mismo careció tanto de un sistema de seguimiento, control y vigilancia, como de medidas de regulación estatal en la extracción. En 1983 el INAPE comenzó



Figura 02: Almejero arrancando almeja en la playa

los estudios poblacionales de la almeja amarilla. En varios relatos se destaca las grandes cantidades extraídas y de la existencia de una cantidad estrepitosa de almejas en la playa. Era frecuente que una parte del trabajo informal se realizara también trayendo mano de obra de Brasil, por pagas sumamente bajas. El circuito de comercialización era principalmente en la modalidad de carnada para pesca deportiva en la capital uruguaya. 


\section{Período de extracción con co-manejo de facto y libre acceso (1987-1993)}

Entre 1987 y 1989 se cerró la pesquería por sobrepesca (Defeo, 1993). El incremento en la abundancia poblacional motivó su reapertura a través de un proceso de co-manejo no institucionalizado que determinó una rápida recuperación del recurso (Defeo, Castilla y Castrejón, 2009). Según otro "almejero", hasta el año 1990 la regulación no tenía mucha complejidad, simplemente se expedían permisos de "pescadores de tierra" por parte del INAPE y con estos ya estaban habilitados para extraer almeja. En 1993, el nuevo gobierno determinó que la pesquería fuera considerada como "autorregulable", volviendo al régimen de libre acceso (Defeo et al., 2009, Gianelli, 2014).

\section{Mortandad masiva y suspensión de la pesquería (1994-2009)}

En el año 1994 se da un evento totalmente atípico en las playas. Las almejas extraídas comenzaron a mostrar un estado de descomposición y putrefacción, observándose mortandades masivas de ejemplares y paulatinamente el recurso comenzó a desaparecer de la playa. Pese a que no existe un consenso en la explicación de este fenómeno regional ya que se registra secuencialmente en costas brasileñas, uruguayas y argentinas (Ortega, Castilla, Espino, Yamashiro y Defeo, 2012; Di Genova, 2018; Dadon, 2013).

\section{Regulación del recurso e implementación de co-manejo (2007-2019)}

A partir del fenómeno de mortandades masivas en 1994 que determinaron la desaparición de almejas de talla comercial, como resultado de un arreglo entre la DINARA y los pescadores se prohibió absolutamente la extracción de almeja amarilla en la zona durante 14 años.

Durante esos años se vendía de forma ilegal a algunos de los intermediarios, aunque como vemos esa situación fue transmitida a los reguladores al retomarse los vínculos entre la DINARA y los almejeros en el año 2007. El proceso de reaparición de la almeja fue complejo, por un lado los almejeros que tenían una relación más cercana a los funcionarios de la DINARA optaron por entrar en contacto con la entidad para poder gestionar el recurso sin ocasionar daños a la especie. Como mencionamos anteriormente, la mortandad ocasionada años anteriores dejó instalada la preocupación por la conservación del recurso y en el discurso la agencia humana tenía un rol protagónico en el desenlace de dicho episodio. Si bien como observamos antes, no fue ésta la única agencia vinculada al fenómeno, y aún no se conocen las causas exactas del episodio, que parece involucrar distintas variables. Sin embargo por ser la agencia humana la más visibilizada adquiere un peso mayor en los relatos, percibiéndose incluso muchas veces un sentimiento de culpa en las palabras de los interlocutores, aunque ellos no hayan participado directamente en las grandes extracciones.

En 2007, en el marco de una reunión con pescadores artesanales y pobladores de la localidad a efectos de consultar sobre la implementación del posible proyecto GEF-DINARAFAO , se mantuvo una conversación con los almejeros a efectos de evaluar la reapertura de la pesquería. Esto finalmente se concretó en el verano de 2009. La decisión tomada por parte de la DINARA para recuperar el recurso y permitir la extracción fue asignar permisos y cupos individuales (anuales) a solicitantes que tuvieran historia en la pesquería y residieran en la zona. Con el apoyo de esas familias y/o permisarios históricos podrían ingresar personas sin antecedentes. En dicha instancia se otorgaron permisos a 29 personas. 


\section{Implementación del Co-manejo en la pesquería de la almeja:}

Entre 2009 y 2011 las decisiones se tomaban a través de asambleas abiertas conformadas por pescadores incluyendo dos coordinadores locales, la Dirección Nacional de Aduanas (Chuy), la Prefectura Nacional Naval (PRENA) y la DINARA y Facultad de Ciencias junto a otras instituciones que participaban de forma eventual como el MIDES (Ministerio de Desarrollo Social), Sindicato Único de Trabajadores del Mar (SUNTMA) y vecinos interesados. Asimismo, el lugar y el vínculo de los pescadores en estas diferentes etapas fue cambiando pero el colectivo de pescadores se fue consolidando como red. Esto pudo haber colaborado a generar un lazo de responsabilidad y cuidado con el recurso, es decir un sentimiento de apropiación del mismo.

Finalmente en el año 2012 como parte de los objetivos del proyecto GEF-DINARA-FAO se establecieron los Consejos de Pesca con frecuencia bianual. El tipo de co-manejo establecido por la ley de pesca fue de carácter "consultivo", donde las decisiones tomadas en estas instancias no son vinculantes para la DINARA (ver Figura 4). Esto se ve reflejado tanto en la implementación de otros Consejos de Pesca (e.g. Trimble y Plummer, 2018), así como también, por el tipo de rol asumido por el Estado en calidad de decisor de todas las resoluciones sobre el manejo del recurso (Ley de Pesca 19.175, Decreto reglamentario 115/018). De acuerdo a la investigación cuantitativa de Pittman et al. (2019), para los pescadores la gestión conjunta ha sido útil para facilitar la participación en los procesos de toma de decisiones de la pesquería y porque se protegieron varios aspectos de sus derechos.

$\mathrm{Al}$ respecto algunos pescadores señalaron, durante nuestro trabajo de campo, que en la propuesta de co-manejo implementada por la DINARA, la responsabilidad implícita de tener que vigilar y controlar a quienes extraen almejas sin permisos, conlleva una "carga muy grande" y no se compensa con los niveles de decisión e incidencia que tienen en las resoluciones (de implementación de vedas y cupos) ni en los muestreos participativos. Al respecto una almejera señalaba que la responsabilidad con el cuidado del recurso se había convertido en "parte del trabajo". En este sentido, la DINARA no realizaba inspecciones regulares en la zona más allá de la asidua presencia de técnicos vinculados al manejo del recurso. Prefectura tuvo un rol importante entre 2008-2011 pero luego esa presencia se desdibujó. Colaço (2010) en su estudio sobre pesca artesanal en la Lagoa Feia en Brasil analiza, como IBAMA es percibido por los pescadores como un riesgo más que deben enfrentar en la jornada de trabajo, por los controles que realizan y no como una garantía o cuidado hacia ellos. En tal sentido, para la almejera que mencionamos anteriormente, el rol que le asignan en la propuesta de co-manejo en vez de ser percibido como un beneficio, derecho u oportunidad, es visto como una carga que se suma al trabajo diario de la extracción, sin tener las garantías necesarias ni respaldo para implementarlo.

Al respecto, cabe mencionar que se podría haber implementado un sistema de seguimiento, control y vigilancia con capacidad inspectiva más presente, a efectos de que la aplicación de la normativa establecida por la DINARA hubiese acompañado el proceso inicial de implementación de co-manejo y que no dependa de la impronta personal y las trayectorias de cada pescador, y tampoco de los técnicos de DINARA sin capacidad inspectiva. Es posible que algunos almejeros permitan la extracción a quien no tiene un permiso otorgado por la DINARA, teniendo en cuenta la necesidad de extraer para cubrir las necesidades alimenticias de su familia. Al respecto un almejero nos cuenta:

H: "Yo soy justo, pero yo no voy a correr a uno que le dicen el Alberto que pesca que arranca alguna almeja para los gurises, que son como siete, ocho gurises pa comer, yo no le voy 
a decir porque estén con unas palas a decir no, no pueden arrancar váyanse, no seas malo." (La Coronilla, setiembre 2018).

Como se desprende de la cita anterior la responsabilidad de cuidar el recurso, debido a las diferentes vicisitudes que se presentan en la pesquería cuando no hay un control directo del Estado, puede volverse más laxa y por momentos conflictiva, ya que el límite en ciertas situaciones, para permitir extraer, más que legal es moral. Al conocer esta situación, para algunos casos donde se daba esta situación, de personas que sacaban almeja sin permiso, se las contactó personalmente por pescadores referentes y/o técnicos de DINARA y fueron incorporados a la pesquerías al año siguiente, evidenciando la importancia de monitorear las políticas públicas de manejo de los recursos en tiempo real de su implementación (Foladori y Taks, 2004, Armitage, Berkes y Doubleday, 2007).

\section{2- Interfases del conocimiento científico y el conocimiento desarrollado en las prácticas de la localidad}

En esta sección se exponen dos acontecimientos que consideramos paradigmáticos para abordar la relación entre conocimiento científico y el conocimiento desarrollado en las prácticas de la localidad. Uno de estos es el episodio de mortandades masivas de almejas, mencionado en la cronología anterior y el otro es el de los muestreos participativos durante la implementación del co-manejo institucionalizado.

Así, comenzaremos por distinguir algunos elementos del conocimiento ecológico desarrollado en las prácticas de la localidad; a lo que Ingold y Kurttila (2000) entienden como aquel conocimiento tradicional generado en las prácticas de localidad por oposición al modelo que llaman genealógico. Dicho conocimiento y sus prácticas asociadas, orienta y sustenta el funcionamiento de sistemas de manejo comunitario, siendo el mismo un conocimiento empírico y práctico, producto de un proceso acumulativo y dinámico de experiencias prácticas y de adaptación al cambio. Es local, holístico y portador de una cosmovisión que integra aspectos múltiples desarrollándose con las personas que se relacionan a diario con sus entornos no humanos. Consideramos que este concepto es útil para abordar los datos empíricos relevados en el presente caso de estudio, pues permite acercarnos a una idea dinámica del conocimiento y al mismo tiempo a un conocimiento y habilidades generadas en las prácticas de la localidad. El mismo está asociado a representaciones simbólicas también compartidas por el grupo y a la identificación común con el entorno de la playa y con la especie objetivo de la pesquería (D’Ambrosio, 2017a, p. 150) en este caso: la almeja amarilla. Este conocimiento está caracterizado por la observación de sus vinculaciones con otras variables que intervienen en el desarrollo de la especie, incluyendo aspectos relacionados a la playa, el clima, los vientos, las marea, la luna, entre otros.

En dicho sentido, se destacan los conocimientos desarrollados por los pescadores durante más de cinco décadas de habitar la zona y practicar la extracción y ,en algunos casos, el procesamiento del recurso. Uno de los elementos destacables es que, si bien todos tienen una amplia variedad de conocimientos, muchas veces estos saberes entran en conflicto o parecen contradecirse. Entendemos que esto puede responder a que la reproducción y resignificación de estos conocimientos ecológicos se da muchas veces en el interior del núcleo familiar y en la práctica, tanto individual como colectiva, de la extracción. Por lo cual es dinámico y puede estar permeado por distintas lógicas y no por una racionalidad homogénea.

Así es que el objetivo de esta sección en este artículo no es desarrollar ni revelar una 
ecología local auténtica y veraz, sino contemplar la amplia gama de saberes, conocimientos, relatos y cosmovisiones que emergen en la interlocución con los actores durante el trabajo etnográfico y analizar sus relaciones con la regulación de la pesquería en vínculo con los conocimientos provenientes del ámbito formal-estatal.

El conocimiento científico a diferencia del local se enmarca, muchas veces en la idea de "especie" y de naturaleza desde una mirada cercana al análisis de Descola (1996) sobre la modernidad, donde la naturaleza es entendida como dominio ontológico autónomo, campo de investigación y experimentación científica. Esto ha llevado a que en algunos momentos el desconocer el conocimiento desarrollado en las prácticas de la localidad, lleve a visiones contrapuestas sobre la presencia o ausencia de almejas para dar comienzo a la pesquería.

La forma de concebir la naturaleza, descripta anteriormente, nos acerca a los postulados del Naturalismo, uno de los modos de identificación, categoría de relación, en el que existe la creencia de que la Naturaleza verdaderamente existe y es definida como una esfera autónoma, desarrollándose en mundos separados del humano, a la cual el procedimiento científico nos permitiría acceder (Descola, 1996). Y en este proceso quedan invisibilizados los procesos de construcción de dicho conocimiento. Por ejemplo, en esta investigación observamos que el hecho de disponer o no de los medios de transporte en el momento más adecuado para realizar los muestreos (aspecto que ha sido mencionado como importante en los procedimientos de muestreos) podría incidir en los resultados. Pues, en caso de no poder concurrir a la playa cuando están dadas las mejores condiciones físicas para realizar el muestreo "la naturaleza" que se construye o capta yendo un día menos propicio, es diferente a la que se podría haber observado de haber podido concurrir en el momento más propicio. No se trata de decir que los hechos no sean reales, sino que los sujetos los construyen mediante formas de interacción que integran su propio camuflaje como parte de la técnica de construcción (Latour y Woolgar, 1986).

Un caso paradigmático en el que se observa esta diferencia entre conocimientos y diferentes modalidades de construir el conocimiento científico, son los muestreos de las evaluaciones de stock poblacional de almeja.

\section{Caso 1: Los muestreos de almejas}

Los muestreos para la estimación de la biomasa disponible para la extracción han sido un elemento clave de la gestión y del desarrollo del co-manejo. Los resultados arrojados en esta instancia de investigación biológica constituyen la principal fuente de datos para determinar la apertura de la pesquería.

Las dinámicas de la especie son muy variables por lo que genera múltiples incertidumbres tanto en los pescadores como en los biólogos, puesto que las almejas pueden un día encontrarse más cercanas a la superficie y al siguiente estar enterradas a una mayor profundidad.

Uno de los elementos fundamentales para catalogar, desde la perspectiva nativa, un muestreo como exitoso o correcto, es la profundidad en la que se buscan las almejas en la arena. De acuerdo a los almejeros, interlocutores de esta investigación, es necesario escarbar al menos hasta un metro de profundidad desde la superficie para encontrarlas, algunas veces. Sin embargo, en algunos casos se han generado conflictos por muestreos realizados sin la inclusión de ese criterio en los muestreos científicos estandarizados y sin la participación de los pescadores en los mismos. Así es que la pesquería se ha visto afectada por lo que para los pescadores es considerado un error metodológico. El error, desde su perspectiva, tiene que ver con la profundidad y la herramienta utilizada, un cilindro plástico, llamado "core", que no 
alcanza la profundidad necesaria para hallar las almejas y que se debe complementar para alcanzar una mayor profundidad con una pala, que forma parte de las artes de pesca de los almejeros. La metodología científica estandarizada la describe el biólogo Jorge de la siguiente forma:

J: “Los muestreos en playas arenosas por lo menos los estandarizados los que más se utilizan, lo más recomendable es hacer estaciones que van de la base de la duna a la base de la zona de barrido de la playa, entonces en el caso puntual, entonces en esos cuatro metros se sacan se utiliza un cilindro que tiene $27 \mathrm{~cm}$ de diámetro y una profundidad de $30 \mathrm{~cm}$ y entonces lo que se hace es con esos cilindros se sacan tres muestras y luego los valores de abundancia o biomasa se estiman para $1 \mathrm{~m} 2$. Entonces con la almeja lo que se hace es una evaluación pesquera desde la zona donde comienza el banco hasta el final de abajo en el agua".

Sin embargo aclara que en la metodología empleada por él, incorpora la visión nativa de la importancia de la profundidad para encontrar al recurso objetivo de la pesquería. En sus palabras nos explica:

J: “Considerando que el cilindro tiene solo 30 centímetros y las almejas se entierran por lo menos a veces medio metro, o sea a veces puede ser más pero por lo menos medio metro deberías tenerlo en cuenta lo que se hace es se agarra una pala pocera de esas que tienen la hoja recta y en el mismo pozo se mete la pala, cosa de llegar de manera de certificar que realmente no hay nada, que sea un cero verdadero, (...). En el agua por ejemplo ya no podes meter la pala, entonces el que saca el pozo, que generalmente soy yo, meto las manos por lo menos hasta acá (codo) y busco con las manos. Entonces con eso certificas de que no hay nada, claro si vos no haces esa búsqueda podés subestimar la muestra, y por lo tanto la biomasa total promedio del transecto. Para estimar biomasa total de la playa (22 kilómetros) se realiza un transecto por kilómetro extrapolando a 500 metros para cada lado del transecto línea y (...) y finalmente sumás todos los transectos. Esa vendría a ser la biomasa total, esa biomasa se estima para pescar, se calcula. Generalmente se hacía en primavera, en primavera empieza a disminuir las tormentas, se empieza a ver mayor ancho de playa. Entonces tenés mayor probabilidad de encontrar el banco digamos, en verano ya las encontrás arriba, si haces el muestreo en verano y estimas la captura y das un cupo, ya llegaste tarde a la zafra, entonces había un balance por lo menos en lo que hacíamos en esos años hasta el 2014. Había un balance entre hacer la evaluación lo más cercano posible a diciembre pero a su vez con el tiempo de que me diera tiempo de hacer la evaluación, y luego hacer y llevar los permisos ..." (La Coronilla, Setiembre 2018).

Como se desprende de la cita anterior en la técnica utilizada por Jorge se da una conjunción de saberes, al muestreo estandarizado de biomasa se incluye el conocimiento de los pescadores desarrollado en la práctica de la localidad. Uno de los hitos de la incorporación del conocimiento de los almejeros en la práctica del muestreo son: los "muestreos participativos" los cuales de acuerdo a un informe presentado por Martínez y de la Rosa (2014) fueron propuestos como "un espacio donde los usuarios pueden conocer la realidad del estado del recurso y tomen conciencia sobre la necesidad de generar medidas de ordenamiento para garantizar la sostenibilidad de recursos naturales (Quiñonero Oltra, 2009). Si bien, en los muestreos realizados por Jorge, siempre se incluía espontáneamente el aporte de los almejeros que se acercaban a la playa al verlo trabajar en búsqueda de almejas, los muestreos participativos formalizaron la participación de los pescadores en una ocasión. 


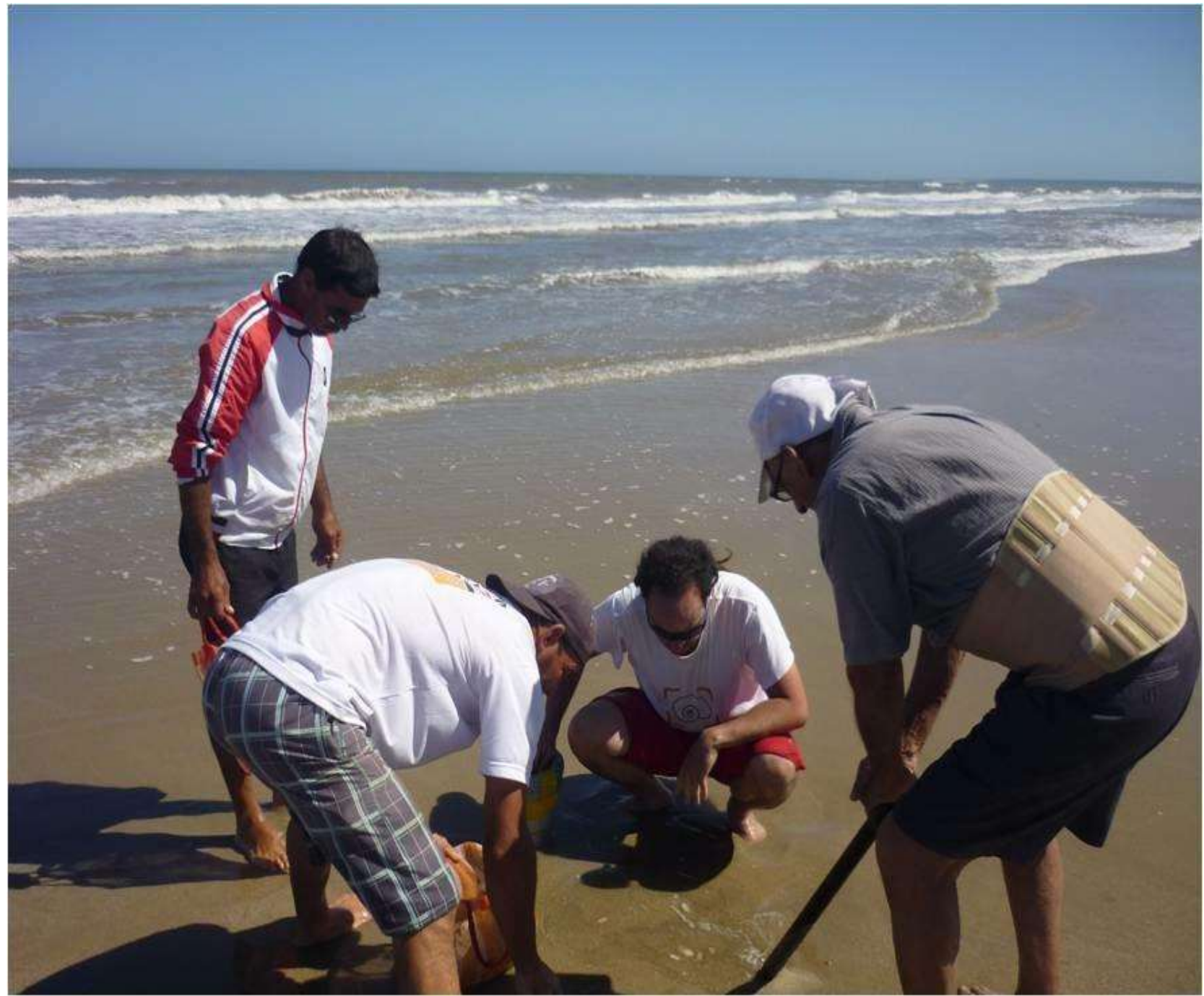

Figura 03: Muestreo participativo de almeja realizado entre biólogos de DINARA y almejeros permisarios.

Aquí la importancia del conocimiento de la playa para elegir el día más indicado para realizar el muestreo, en palabras de Jorge fue reforzado por la experiencia y el conocimiento transmitido por los pescadores. Vemos como en las posibilidades de encontrar almejas o no, podía incidir el conocer el estado de la playa, por lo que en estos muestreos incidía la información aportada por el almejero que monitorea la playa en el día a día, por encontrarse allí, e informar al científico sobre ello.

Podemos decir que el resultado de los monitoreos, tanto los permeados por el conocimiento nativo como por los estandarizados (que no incluyen dicho conocimiento), constituyen "híbridos de naturaleza-cultura" (Latour, 2005). En los dos casos la agencia y decisiones humanas inciden en los resultados del muestreo. Sin embargo, estas agencias no son explicitadas ni visibilizadas por los investigadores, por el contrario, pasan desapercibidas. Es a partir del análisis que realizamos de los datos que relevamos durante el trabajo de campo con almejeros y biólogos que resaltamos estos aspectos fundamentales en el proceso de generación de datos biológicos sobre la pesquería y la especie.

Como se puede observar la implementación de los muestreos participativos tiene diversos efectos que trascienden los objetivos planteados por los proponentes, que se 
enfocaban principalmente en incluir a los almejeros en el proceso de muestreo para informarlos. Sin embargo, observamos que por un lado, tiene la capacidad de generar un resultado positivo empleando técnicas efectivas para la localización de las almejas. Por otro, genera legitimación del conocimiento de los pescadores, ya que es puesto en práctica y considerado por las autoridades encargadas de gestionar el recurso y por los científicos vinculados a la misma.

Asimismo, en estos encuentros el conocimiento científico es transmitido a los almejeros, quienes pueden conocer la perspectiva y metodología utilizada, tan trascendentales para ellos, por su relevancia para determinar la apertura.

Es importante señalar que si bien se buscó que los muestreos participativos se incorporaran como una constante en el modelo de co-manejo de la pesquería, como lo señala Martínez y de la Rosa, 2014, "esta actividad quedará incorporada en el plan de manejo pesquero del recurso", los mismos se dejaron de realizar. Actualmente depende del investigador a cargo del muestreo y de su interés en incorporar a los pescadores en el mismo. Tampoco se formalizó la metodología que nace de la conjunción de ambas perspectivas, sino que la misma fue incorporada espontáneamente por algunos investigadores interesados en la perspectiva de los pescadores sobre el recurso, pero el conocimiento ecológico desarrollado en las prácticas de la localidad no ha sido, hasta el momento, legitimado formalmente.

\section{Caso 2: La gran mortandad: explicaciones del conocimiento desarrollado en las prácticas de la localidad}

En Uruguay, en el año 1994 hubo una gran mortandad de almejas durante la cual las almejas extraídas se pudrían y tomaban un color negro intenso. En poco tiempo la especie desapareció de la playa. Ante dicho suceso surgieron diferentes explicaciones. Cada uno de los almejeros tiene su explicación para el fenómeno.

Según cuenta Humberto, uno de los almejeros de más larga trayectoria en la pesquería, notó que algo raro sucedía con la almeja, la encontró que estaba enferma:

H: “Sí, vi que, digo no, aquí pasa algo, negra la almeja. Empezó a venir muerta. Negra quedó, entonces digo, paren no, no arranquen, no arranquen que esto está enfermo, paren, vamos a llamar a DINARA, esto aquí (...) Miles de toneladas se murieron. Entonces comprobé que era... fue cuando vino Simón [técnico de DINARA], lo hablé con Simón enseguida, mira no sé qué pasa aquí pero esto, se está muriendo toda la almeja. Y vino y mirá, una marea roja dice... Pero, y ahí se terminó la almeja. Ahí se terminó la almeja. Se liquidó." (La Coronilla, setiembre 2018).

Para él eso se debió a un desprendimiento de algas producido por la gran circulación de barcos pesqueros de gran calado en una zona a trescientos metros de la costa donde existe una cordillera de rocas subacuática:

H: "Yo arranqué ese día la almeja sana, bien, bien, bien. Se ve que ya estaba infestada, se ve que ese día (...) Porque yo se la llevé especial y de noche me llama el loco que empieza a quedar negra... Bueno y yo me puse a estudiar y saqué la conclusión, bien sacada, bien y era, y es todavía sigue siendo. A 300 metros de la costa hay una cordillera de piedra que llega a Brasil, sigue pa allá pa Brasil no sé hasta donde sigue, pero yo sé que acá hay una cordillera de piedra 
que llega hasta allá, pero, adentro del mar, hay un alga, de no sé cómo se llama, yo no sé (...) Que es un repollito blanco, una alga blanca, un repollito blanco que cuando hay mar de fondo, mucho se arranca".

\section{Et: "Ah porque está pegada a esa cordillera."}

H: “Claro. Pero también hay en la playa, en la arena eso, se agarra como cuando mira una película que ve que las flores y las plantas agarradas en la arena abajo ¿verdad no? Bueno, ahí también hay, que pasa... Con las pescas de arrastre (...) Yo conté un día 33 barcos brasileros. (...) Los conté, los miré, habían 5 pasando la cordillera, allí al lado de la cordillera, pescando de arrastre, con las redes de un barco a otro, y al otro día de haber pescado, de haber estado ese barco, al otro día de haber estado ese barco empezaron a salir las algas blancas..." (La Coronilla, setiembre 2018).

Por su parte Antonio, primo de Humberto, las encontró todas muertas y negras. Piensa que se pudo deber a algún químico arrastrado por el canal Andreoni desde los campos arroceros de la zona:

Et: “¿Y vos ahí cuando viste la mortandad, ¿qué pensaste?”

A: "Yo te digo ya lo que pensé, yo siempre pensé que había sido el canal.

Et: “¿Por el canal?”

A: "Por el canal, pensamos digo algún este... química del arrocero (...) Entonces yo digo, le digo a mi sobrino, las almejas desaparecieron no están entonces empezamos a catear por aquí por allí, catear es meter la pala, de repente metimos la pala cerca de donde estaban

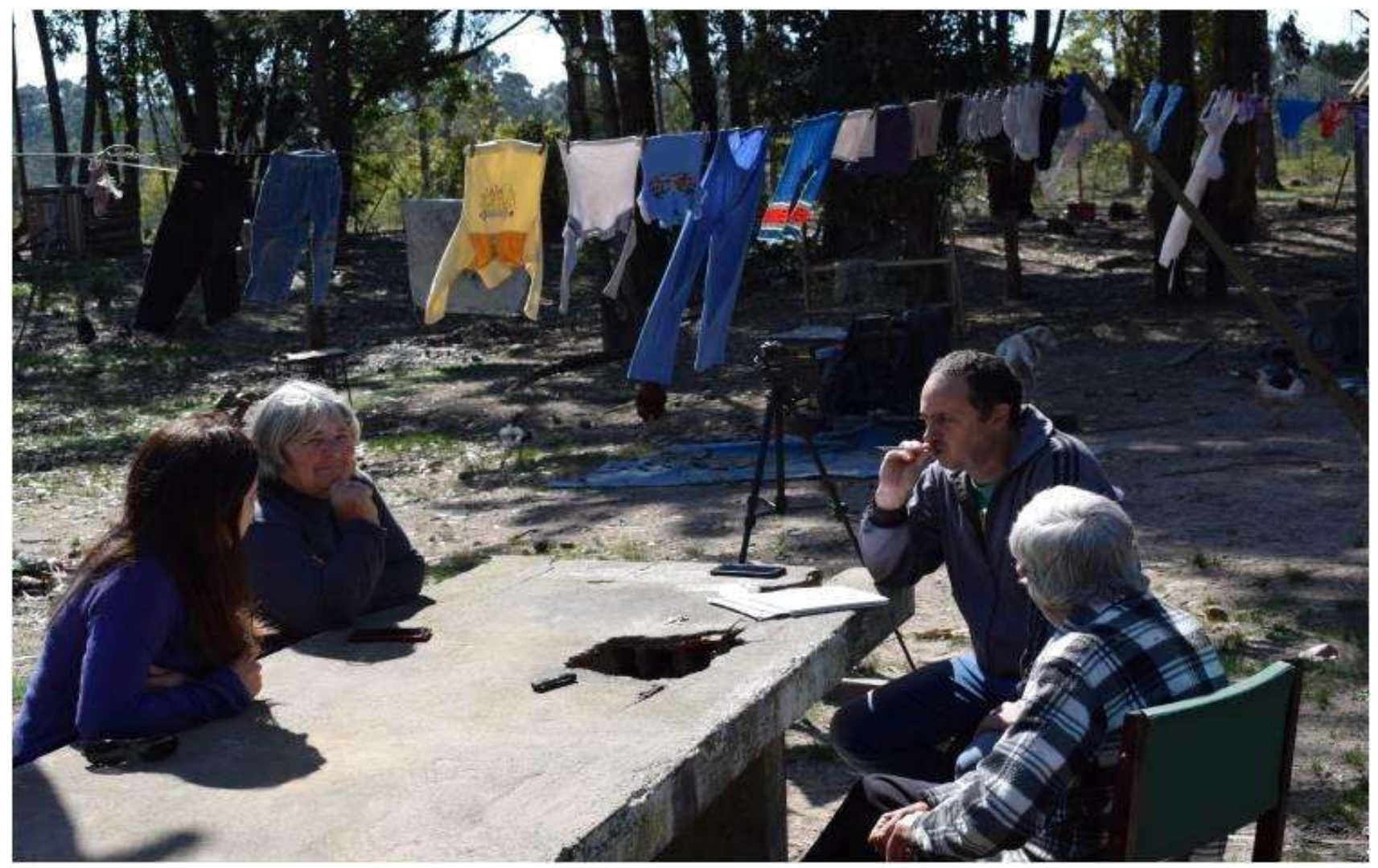

Figura 04: Entrevista etnográfica con familia almejera y biólogo ex DINARA 
arrancadas del día anterior habíamos arrancado, de repente pero cuando metimos la pala hicieron crack... metimos la pala pa' bajo y sacamos y estaba todo podrido, la arena negra, las almejas con los cuernitos y la lengüita de afuera así muriéndose y un olor a podrido que nos hicimos unas arcadas y coso y yo le digo se están muriendo, mira las almejas se están muriendo y no podíamos creer nosotros."

Por su parte Nidia considera que pudo haber sido un comportamiento natural de la almeja, que se fue hacia dentro del agua para reproducirse y luego volvió a salir a la faja de playa:

Et: “ ¿Y ustedes por qué piensan que fue esa época que no hubo que fue la mortandad, a qué se debió para ustedes?"

$\mathrm{N}$ : "Y en verdad no sabemos bien que fue porque, opciones hubo de arrancadores viejos, mi padre mil veces me decía que la almeja se había ido para adentro a reproducir y que por eso no había almeja afuera. Porque era muy poca la almeja que había."

Et: "Y vos qué pensás de eso ¿para vos qué fue?"

$\mathrm{N}$ : "Y si ellos lo decían que eran más viejos que nosotros, para mi sigue el mismo sistema."

Et: "¿Si?"

$\mathrm{N}$ : "Y sí. Porque después en años y años fue, porque a veces nos preguntamos y ¿de dónde fue que salió? Eso fue un banco que estaba adentro de la playa. Pa mi era un banco que estaba dentro de costa (...)"

Et: "Vos decís que fue como un comportamiento natural de almeja nomás que se fue para adentro y (...)"

N: "Natural, hizo la reproducción fue que se largó para afuera. Creo yo, porque no puedo creer que hubiese estado tan bajo, en las partes secas, tan metida para adentro para después salir. No lo veo en esas opciones."

(La Coronilla, setiembre 2018).

Por otro lado Julio piensa que pudo deberse a las olas de calor de la época:

Et: “¿Y para ustedes por qué fue que hubo esa mortandad así que desapareció?”

J: "Dicen que en esa época realmente hubo una marea roja que dicen que, todo lo que me contaban, porque yo era chico, uno a veces se olvida de las cosas y no pone atención en las cosas de los grandes ¿no? Dicen que mataba hasta a las gallinas, los bichos que había cerca de la playa mataban y hubieron unas olas de calor y todo eso que fue cuando se terminó, bueno pa' encontrar una almeja caminabas un kilómetro y encontrabas una, tenías alguna pala así pasabas." (La Coronilla, setiembre 2018)

Como se ve en los pasajes anteriores, muchos de los pescadores de almeja tienen una o varias explicaciones posibles para este suceso tan extraordinario que los privó de la especie objetivo de la pesquería durante mucho tiempo. El interés por explicar la situación no se agotó en sus conjeturas u observaciones en la playa, sino que algunos recurrieron a los científicos para consultarles al respecto. Así es que Antonio, generó comunicaciones con DINARA buscando alguna respuesta al tema, en el siguiente extracto de entrevista lo detalla:

A: "Y llamamos, yo llamé a DINARA y dije, bueno vengan, vengan este que las almejas...a ver creo que Jorge no estaba todavía, estaba Simón no estaba Jorge, vengan que las almejas aquí 
hay un problema ta' todo podrido las almejas se pudrieron todas, se están muriendo todas, bueno si yo te digo, mira que yo quiero la playa, quiero la playa porque yo nací me crié y tu sabes lo que es lloré por eso, porque podía juntar podía juntar con una pala, una pala de esas mecánicas, juntar así camiones."

Pero tampoco los biólogos consultados pudieron dar una explicación concluyente al asunto en aquel momento, al respecto Humberto relata:

Et: “¿Y no se sabe por qué?”

A: "Supuestamente, supuestamente, me contó Simón y me contó Jorge que fue una toxina que se les alojó a las almejas en el estómago y que las mató ¿no? pero nunca pudieron descubrir qué fue."

\section{La gran mortandad según el conocimiento científico}

El conocimiento científico analizó las causas teniendo en cuenta desde el inicio, que representó un fenómeno regional. Este proceso de mortandades masivas se iniciaron en Brasil en 1993 (350 km de playas entre los paralelos $30^{\circ}$ y 33으), continuaron en Uruguay en 1994 (22 km de playa, 750.000 almejas, ca. 9 ton) y en Argentina (63 millones y 428 ton) se comienzan a registrar las mortandades en el año 1995 (Méndez, 1995, Odebrecht, Reorig, García y Abreu, 1995, Fiori y Cazzaniga, 1999). Las primeras investigaciones reportaron la ocurrencia de floraciones de algas tóxicas en Uruguay y en Brasil, y las vincularon a estas mortandades (Méndez, 1995, Odebrecht et al., 1995, Ferrari, Méndez y Brazeiro 2000). Luego se registraron anomalías de temperatura en la costa uruguaya (años cálidos) a partir de 1996 (Ortega, Celentano, Delgado y Defeo, 2016), siendo dos años después del proceso de mortandades masivas. Lo anterior explicaría procesos de declinaciones poblacionales y prevalencia de anormalidades corporales luego de ese año a la actualidad (Ortega et al., 2012 y Ortega et al., 2016). Si bien las anomalías de temperatura no explicarían la mortandad de 1994, si permitió detectar un proceso de calentamiento que se ha ido consolidando, y como consecuencia que tanto Uruguay y parte de Argentina actualmente constituirían una zona caliente (Mooney, Muyskens y Van Houten, 2019).

Otras investigaciones han propuesto otras hipótesis para explicar estos eventos episódicos de mortandad buscando un agente etiológico (sensu Vázquez, Fiori, Arzul, Carcedo y Cremonte, 2016) como responsable de la misma. En este sentido, se ha detectado la presencia de parásitos (Cremonte y Figueras, 2004, Fiori et al, 2004 y Brusa, Ponce de León y Damborenea, 2006) y bacterias del género Rickettsia (Carvalho, Poersch y Romano, 2013). Carvalho, Da Silva, Raibenberg, Poersch y Romano, (2016) y Vázquez et al., (2016) analizando la presencia de parásitos y sus patologías asociadas, y OsHV-1 (herpes virus) en almejas de Brasil y en Argentina (luego de una mortandad registrada en 2008 en Monte Hermoso), tampoco detectaron resultados concluyentes. Finalmente, Thompson y Sánchez (2004) encontraron que la mortandad registrada en Buenos Aires fue el resultado de un evento aislado de contaminación con metales pesados.

Las explicaciones científicas tampoco llegan a una única explicación que dé cuenta de las mortandades a pesar de que el fenómeno tuvo una magnitud regional y algunas de las investigaciones desarrolladas en Argentina y Brasil han ido más en profundidad, tampoco han alcanzado explicaciones concluyentes.

La falta de resultados concluyentes sobre las mortandades masivas coloca a esta pesquería en un lugar con varias incertidumbres respecto a su futuro. Lo anterior junto al 
proceso de calentamiento registrado en Uruguay y Argentina, justifican el mantenimiento del estado de conservación de la almeja amarilla como vulnerable, según los criterios de la UICN (Unión internacional para la Conservación de la Naturaleza). No obstante el proceso de comanejo junto a los cambios en la comercialización generados por las piletas de Almejas Palmares, y el vínculo pescadores-DINARA-academia, podrían estar sorteando las dificultades a los factores externos e internos que afectan a la pesquería y haber asegurado la sostenibilidad hasta la fecha.

\section{3- Vinculaciones entre los diversos actores vinculados a la pesquería}

Para comprender las conexiones entre conocimientos desarrollados en torno a la pesquería, nos detendremos en el vínculo desarrollado entre los pescadores y los actores estatales en cuestión. A lo largo de los años, los almejeros de la zona han tenido contactos frecuentes con la DINARA, ya sea para informar o alertar de la situación del recurso, organizar encuentros y coordinar actividades, resolver problemáticas, solicitar que instauren o retiren la veda, entre otras cosas. Cabe destacar las relaciones cercanas que se establecieron entre dos funcionarios de dicha institución (biólogos) y los almejeros, por ejemplo Humberto (almejero) trabajó como enlace con la DINARA con respecto a la almeja, había entablado un vínculo con Simón (funcionario de DINARA) de gran cercanía. Al respecto nos cuenta:

H: "Bueno, y ahí empecé, y después dejé de arrancar almeja cuando empecé a trabajar en DINARA, y cuando dejé de trabajar en DINARA fue cuando me enfermé, entonces otra vez estuve en DINARA y hablé con Simón y le dije, Simón. - ¿Cómo andas Humberto, cómo estás? Somos como hermanos con Simón porque nos conocemos de toda una vida (...)." (La Coronilla,

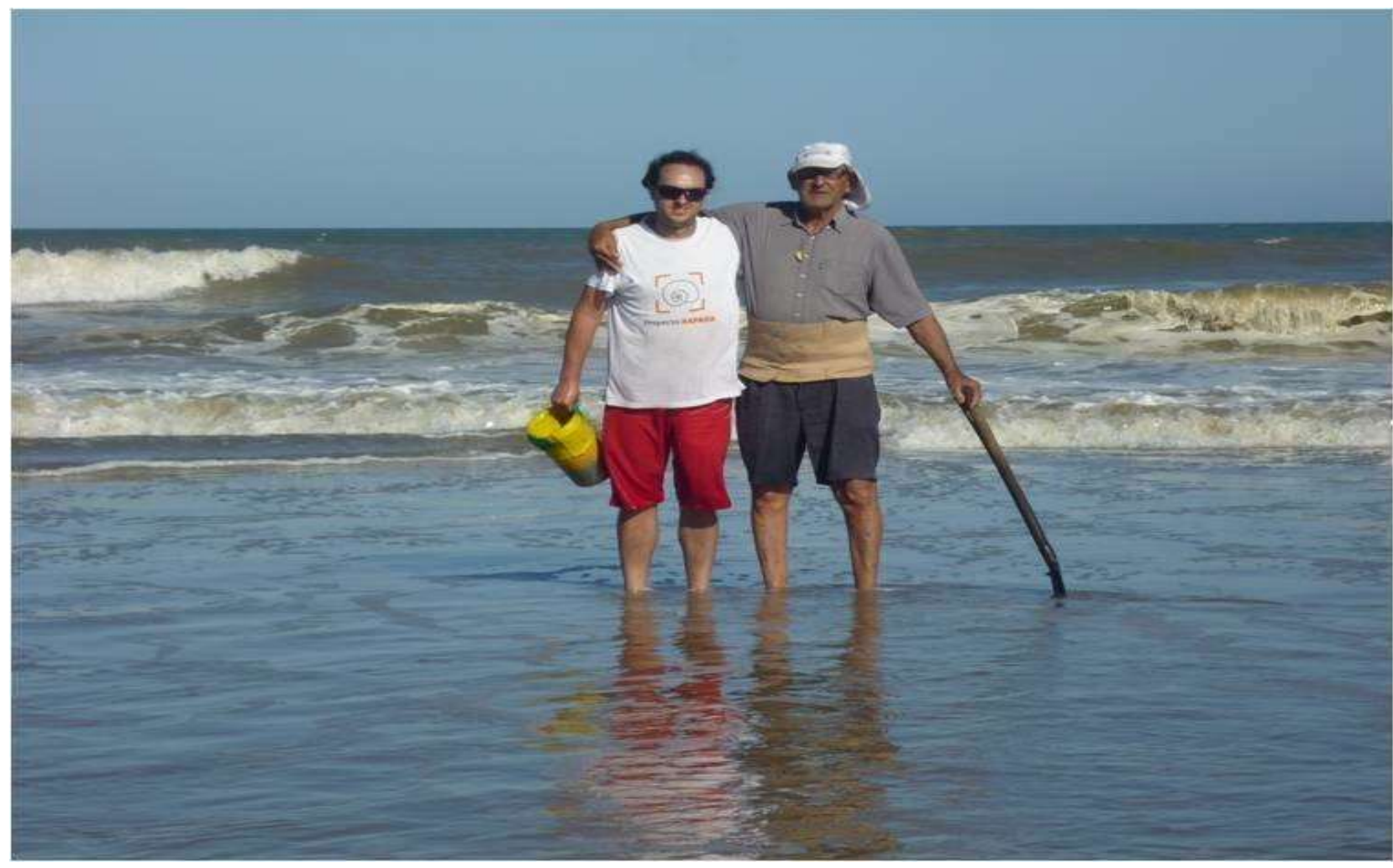

setiembre 2018). Figura 05: Almejero y biólogo abrazados durante un muestreo participativo 
A su vez el pescador señalaba que con frecuencia intercambiaban opiniones con los biólogos sobre la almeja así como datos de diferentes tipos al respecto de la especie o la situación. El vínculo estrecho entre ambos actores sociales, el estatal y el local, así como la valorización y articulación de los conocimientos y saberes de ambos generan un vínculo de responsabilidad de los explotadores del recurso para con la preservación.

Así es que algunas instancias determinantes para la pesquería se han visto revestidas y enriquecidas por una articulación de conocimientos entre los científicos y los pescadores. Sin embargo, esta riqueza de intercambios y retroalimentaciones si no es sistematizada, objetivada e institucionalizada, corre el riesgo de perderse con las personas que pueden alejarse de la pesquería. Pues frecuentemente se observa un vínculo cercano y espontáneo entre personas que generó prácticas conjuntas de gestión del recurso pero no institucionalizadas hasta el momento.

\section{Conclusiones: intercambios de conocimiento y el enfoque etnográfico}

A modo de cierre es posible decir que vemos como claramente existe un vínculo sumamente cercano y de afinidad entre los gestores-investigadores del Estado y algunos pescadores. Éste, sin dudas, es alimentado por un interés común: la preservación de las almejas para una extracción sostenible en el tiempo. En tal sentido, la circulación de saberes se da de una manera recíproca. Los pescadores por ejemplo transfieren sus saberes sobre las variantes climáticas y ecológicas desarrollados a partir de la observación cotidiana de la playa y el contacto directo con el entorno. Por contrapartida, los biólogos aportan información en relación a las características biológicas de la especie, sus propiedades morfológicas, sus ciclos naturales y de reproducción y establecen la cantidad de almejas a extraer.

En este artículo buscamos enfatizar la importancia de dar cuenta de la interrelación de saberes, pues, como analizamos anteriormente muchos de los intercambios y la implementación de medidas de manejo conjuntas dependieron de la voluntad e interés de los investigadores involucrados y no fueron institucionalizadas como medidas de gestión desde los organismos encargados de la gestión.

Asimismo, observamos que otros aspectos que se generaron en el proceso de comanejo han pasado desapercibidos y que sin embargo dan cuenta de la confianza depositada en los pescadores por parte de los gestores, lo que ha sido un factor significativo para comprender estas relaciones. Ya que la confianza proviene del reconocimiento a una larga trayectoria en el oficio. Este reconocimiento genera el efecto de legitimidad buscado por los pescadores para recibir su permiso de pesca y, lo que va aún más allá, otorgarlo a otros. Este factor tiene una doble capacidad, por un lado refuerza en los pescadores un sentido de pertenencia con la pesquería y valorización de su conocimiento si bien, el conocimiento ecológico desarrollado en las prácticas de la localidad no ha sido, hasta el momento, legitimado formalmente. Por otro, genera un efecto de responsabilidad frente al recurso, siendo los pescadores los actores sociales designados consuetudinariamente para supervisar la explotación irregular. Si bien, como analizamos anteriormente, esta responsabilidad no es vista con muy buenos ojos por algunos de los pescadores, puesto que no sienten garantías para poder ejercer el control sobre la extracción ilegítima. Dada la escasa presencia estatal y que este rol no es acompañado de la posibilidad de decidir sobre la condiciones de explotación del recurso (Consejo de Pesca de carácter consultivo). El mapeo de esta perspectiva nativa del proceso pone de manifiesto la importancia del monitoreo en tiempo real de las medidas de co-manejo.

Finalmente destacamos que la metodología empleada en esta investigación nos permitió 
mapear las diversas perspectivas en torno a la implementación del co-manejo, así como analizar las interrelaciones entre tipos de conocimientos y los procesos de construcción de los datos y su procesamiento que pueden pasar desapercibidos con otros abordajes. El abordaje etnográfico nos permitió, no solo captar la perspectiva nativa, sino que apreciar los grises, la heterogeneidad de posiciones entre los pescadores así como también entre los científicos y mapear "híbridos de naturalezas-culturas".

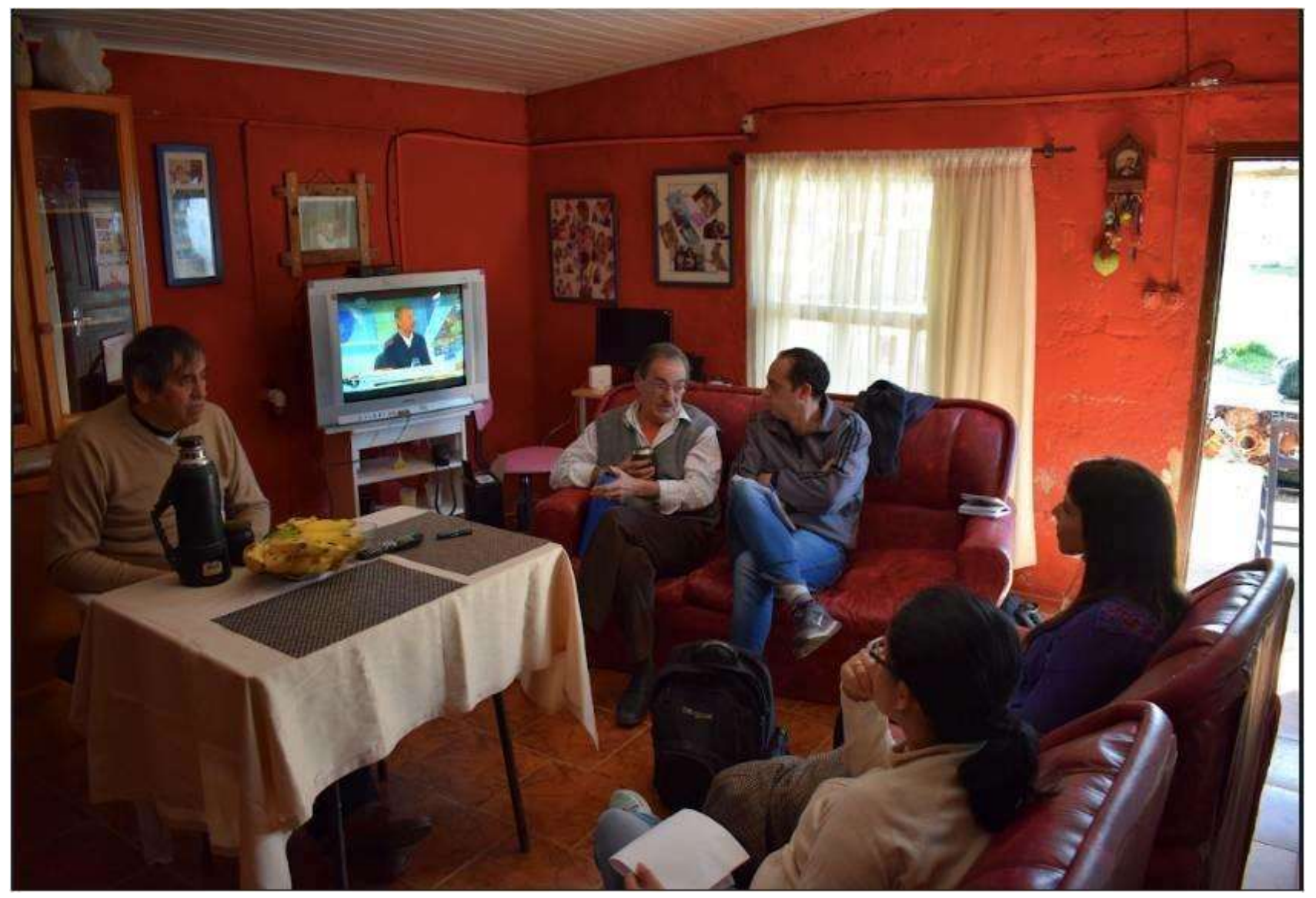

Figura 06: Instancia de entrevista etnográfica con almejeros en La Coronilla.

\section{Referencias}

Armitage, D., Berkes, F. y Doubleday, N. (2007). Introduction: moving beyond co-management. En: D. Armitage, F. Berkes, y N. Doubleday (Ed.), Adaptive Co-Management: Collaboration, Learning and Multi-Level Governance. Toronto, Canada: UBCPress.

Brusa, F., Ponce de León, R. y Damborenea, C. (2006). A new Paravortex (Platyhelminthes, Dalyellioida) endoparasite of Mesodesma mactroides (Bivalvia, Mesodesmatidae) from Uruguay. En: Parasitology research, 99, pp. 566-71.

Carvalho, Y. B. M., Poersch, L. H. y Romano, L.A. (2013). Rickettsia-associated mortality of the yellow clam Mesodesma mactroides (Bivalvia: Mesodesmatidae) in southern Brazil. En: 
Malacologia. 56, pp. 301-307.

Carvalho, Y. B. M. y Da Silva, J.J.S., Raibenberg, F.C., Poersch, L.H., y Romano, L.A. (2016). Use of polymerase chain reaction for bivalve pathogen surveillance in the yellow clam Mesodesma mactroides. J. Aquat. Anim. En: Health. 28, pp. 114-117.

Cremonte, F. y Figueras, A. (2004). Parasites as possible cause of mass mortalities of the critically endangered clam Mesodesma mactroides on the Atlantic coast of Argentina. En: Bull. Eur. Assoc. Fish Pathol. 24, pp. 166-171.

Colaço, J. (2010). Pescador que é pescador enfrenta ate IBAMA!: notas para etnografía de un conflito na Lagoa Feia. En: G. Adomilli, L. D'Ambrosio, G. Carreño y F.S. Miller (Orgs.), "Povos e coletivos pesqueiros. Estudios etnográficos e perspectivas socioantropológicas sobre o viver e o trabahlar. Rio Grande, Brasil: Editora Furg.

D’Ambrosio, L. (2017a). La experimentación perceptual de la costa y el mar: Un estudio con surfistas, biólogos y pescadores artesanales. Revista Tessituras Furg. Brasil.

Decreto reglamentario 115/018. Reglamentación de la ley 19.175. Recuperado de: https://www.impo.com.uy/bases/decretos/115-2018/68.

Defeo, O. (1989). Development and management of artisanal fishery for yellow clam Mesodesma mactroides in Uruguay. Fishbyte 7(3), pp. 21-25.

Defeo, 0. (1993). The effect of spatial scales in population dynamics and modelling of sedentary fisheries: the yellow clam Mesodesma mactroides of an Uruguayan exposed sandy beach. (Tesis de Doctorado). CINVESTAV-IPN Unidad Mérida. 308 pp (Inédita).

Defeo, 0. (2003). Marine invertebrate fisheries in sandy beaches: an overview. J. Coast. Res. 35, pp. 56-65.

Defeo, 0., Castilla J. y Castrejón M. (2009). Pesquerías artesanales de invertebrados en América Latina: paradigmas emergentes de manejo y gobernanza. Foro Iberoam Rec Mar Acui II, pp. 89117.

Defeo, O., Gianelli, I., Martínez, G., Ortega, L., Celentano, E., Lercari, D. y De la Rosa A. (2018). Natural, social and governance responses of a small-scale fishery to mass mortalities: the yellow clam Mesodesma mactroides in Uruguay. En: P. Guillotreau, A. Bundy y R. Ian Perry. (Ed), Societal and governing responses to global change in marine systems (Cap. 17). New York, Routledge Studies in Environment, Culture, and Society Series. 
Descola, P. (1996). Constructing Natures: Symbolic Ecology and Social Practice. En: Descola, P. y Pálsson, G. (Comps.) Nature and Society: anthropological perspectives. London: Routledge.

Di Genova, F. (2018). Por qué los argentinos ya no podemos comer almejas. Recuperado de: https://www.lanacion.com.ar/lifestyle/por-que-los-argentinos-ya-no-podemos-comeralmejas-nid2107134

Ferrari, G., Méndez, S. y Brazeiro, A. (2000). Dinophysis acuminata associated to diarrehtic shellfish poisoning reports in Uruguay. Frente Marítimo 18(A), pp. 91-95.

Fiori, S. M. y Cazzaniga, N.J. (1999). Mass mortality of the yellow clam, Mesodesma mactroides (Bivalvia: Mactracea) in Monte Hermoso beach. Argentina. Biol. Conserv. 89, pp. 305-309.

Fiori, S. M., Vidal-Martınez V. M., Sima-Alvarez,R., Rodrıguez-Canul, R., Aguirre-Macedo, M.L. y Defeo, 0. (2004). Field and laboratory observations on the mass mortality of the yellow clam Mesodesma mactroides in South America: the case of Isla del Jabal, Argentina. J. Shellfish Res. 23, pp. 451-455.

Foladori, G. y Taks, J. (2004) Um olhar antropológico sobre a questão ambiental. Mana [online]. 10(2), pp.323-348. ISSN 0104-9313.

Gianelli, I. (2014). Impacto del co-manejo en la pesquería de la almeja amarilla de Uruguay, en base a indicadores bioeconómicos. (Tesina de grado de la Licenciatura en Ciencias Biológicas) UdelaR-Montevideo, Uruguay.

Gianelli, I., Martínez, G. y Defeo, O. (2015). An ecosystem approach to small-scale co-managed fisheries: the yellow clam fishery in Uruguay. Marine Policy 62, pp. 196-202.

Ingold, T. y Kurtilla, T. (2000) Perceiving the Environment in Finnish Lapland.

Body \& Society 6, pp. 183-196.

Latour, B. (2005). Reensamblar lo social. Una introducción a la teoría del actor red. Buenos Aires, Argentina: Manantial.

Latour, B. y Woolgar, S. (1986). Laboratory Life. The Construction of Cientific Facts. New Jersey, U.S.A.: Princeton University Press.

Ley de Pesca $\mathrm{N}^{\circ}$ 19.175, 20 de diciembre de 2013. Recuperado de: https://www.impo.com.uy/bases/leyes/19175-2013/12

Manta, G., Barreiro, M., Ortega, L. y Defeo, O. (2017). The Effect of Climate Variability on the Abundance of the Sandy Beach Clam (Mesodesma mactroides). The Southwestern Atlantic 
Journal of Coastal Research 33(3), pp. 531-536.

Martínez, G. y de la Rosa, A. (2014). Muestreo participativo junto a los pescadores, del gremio de filtradores en la franja costera entre la localidad de Barra del Chuy y el Área Costera Protegida de Cerro Verde e Islas de la Coronilla. Informe interno FAO-DINARA.

Mendez, S. (1995). Bivalve mortality on southwest Atlantic shores. Harmful Algae News 10(11), pp. 12-13.

Mooney, C., Muyskens, J. y Van Houten, C. (2019). Dangerous new hot zones are spreading around the world. Washington Post. Recuperado de: https://www.washingtonpost.com/graphics/2019/national/climateenvironment/climatechange-world/)

Odebrecht, C., Reorig, L., Garcia, L, V. T. y Abreu, P. C. (1995). Shellfish mortality and red tide event in southern Brazil. En: P. Lassus (Ed.). Harmful mar algal blooms (pp. 213-218). New York, U.S.A.: Springer-Verlag.

Ortega, L., Castilla, J.C., Espino, M., Yamashiro, C. y Defeo, O. (2012). Effects of fishing, market price, and climate on two South American clam species. En: Marine Ecology Progress Series, 469 , pp. 71- 85.

Ortega, L., Celentano, E., Delgado, E. y Defeo, O. (2016). Climate change influences on abundance, individual size and body abnormalities in a sandy beach clam. Marine Ecology Progress Series 545, pp. 203-213.

Pittman, J., Gianelli, I., Trinchín, R., Gutiérrez, N., De la Rosa, A., Martínez, G., Masello, A. y Defeo, O. (2019) Securing sustainable small-scale fisheries through co management: the yellow clam fishery in Uruguay. En: L. Westlund y J. Zelasney (Eds.), Securing sustainable small-scale fisheries: sharing good practices from around the world. Fisheries and Aquaculture Technical Paper No. 644 (pp.9-37). Roma, Italia: FAO.

Quiñonero Oltra, J. (2009). La Investigación Participativa como forma de resolución colaborativa de problemas e incremento de la autonomía de los grupos locales. Cuadernos CIMAS-Observatorio Internacional de Ciudadanía y Medio Ambiente Sostenible. Recuperado de: http://www.redcimas.org/biblioteca/metodologia/)

Thompson, G. A. y Sánchez de Bock, M.F. (2004). Mortandad masiva de Mesodesma mactroides (Bivalvia: Mactracea) en el partido de la costa, Buenos Aires, Argentina, en septiembre 2004. Atlantica (Rio Grande) 29, pp. 115-119. 
Trimble, M. y Plummer, R. (2018). Participatory evaluation in times of governance transition: The case of small-scale fisheries in Uruguay. Ocean \& Coastal Management 161, pp. 74-83.

Vázquez, N., Fiori, S., Arzul, I., Carcedo, C. y Cremonte, F. (2016). Mass Mortalities Affecting Populations of the Yellow Clam Amarilladesma mactroides Along Its Geographic Range. Journal of Shellfish Research 35(4), pp. 739-745. 